\title{
Measuring the relative efficiencies of automated telling machines and point of sales
}

\author{
Sara Farajzadeh*
}

Department of Business and Management, Digital Unit, Iran University of Science and Technology, Tehran, Iran

\begin{tabular}{|c|c|}
\hline CHRON I C LE & A B S T RACT \\
\hline $\begin{array}{l}\text { Article history: } \\
\text { Received June 5, } 2015 \\
\text { Received in revised format } \\
\text { August } 162015 \\
\text { Accepted December } 212015 \\
\text { Available online } \\
\text { December } 242015 \\
\text { Keywords: }\end{array}$ & $\begin{array}{l}\text { During the past few years, many people have been interested in purchasing goods and services } \\
\text { via point of sales (POS). They have also wished to pay their bills, withdraw cash or transfer } \\
\text { funds using automated telling machines (ATMs). These two facilities help banks' customers } \\
\text { carry less amount of cash and do their daily banking activities any time even when the banks } \\
\text { are closed. This paper presents an empirical investigation to measure the relative efficiency of } \\
\text { nearly } 600 \text { POS and ATM units associated with Bank Melli Iran located in city of Tehran, Iran. } \\
\text { Using data envelopment analysis, the study has disclosed that only small portions of POS and } \\
\text { ATM are working efficiently. }\end{array}$ \\
\hline
\end{tabular}

Point of sales

Automated telling machines

\section{Introduction}

During the past few years, many people have been interested in purchasing goods and services via point of sales (POS). They also wish to pay their bills, withdraw cash or transfer funds using automated telling machines (ATMs). These two facilities help banks' customers carry less amount of cash and do their daily banking activities any time even when banks are closed. One primary question may appear is to know how efficient these machines are and whether there are methods to improve the efficiencies of these kinds of facilities. Camanho and Dyson (1999) applied data envelopment analysis (DEA) to measure the efficiency of different Portuguese bank branches where ATMs activities were considered as part of bank efficiency. Pasiouras (2008) implemented a sample of 715 banks from 95 countries and two-stage DEA to provide international evidence on the effect of regulations and supervision approaches on banks' efficiency. Cook et al. (2004) investigated the relative efficiencies of some selected banks based on different banks' activities including ATMs and POSs. Point of sales devices are believed to be secured system for purchasing goods and services (Yang et al., 2007). Evans et al. (1999) investigated the organizational factors contributing to the successful commingling of employee service and sales responsibilities at the point of customer contact.

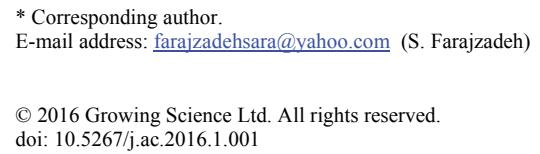




\section{The proposed study}

This paper presents an empirical investigation to measure the relative efficiencies of nearly 600 POSs and ATMs, which are serving Bank Melli Iran. The proposed study of this paper uses data envelopment analysis to measure the efficiency of these banks. The constant return to scale DEA (CCR) was initially developed by Charnes, et al. $(1978,1994)$ as a tool for stuyding the relative efficiency of decision making units (DMU) where there are several inputs/outputs. In DEA, a set of production feasibility which includes some principles such as fixed-scale efficiency, convexity and feasibility is defind as follows,

$$
T_{C}=\left\{(X, Y) \mid X \geq \sum_{j=1}^{n} \lambda_{j} X_{j}, Y \leq \sum_{j=1}^{n} \lambda_{j} Y_{j}, \lambda_{j} \geq 0, j=1, \cdots n\right\},
$$

where $X$ and $Y$ are the input and output vectors, respectively. The CCR production feasibility set border describes the relative efficiency in which any off-border DMU is stated as inefficient. The CCR model can be implemented in two forms of input/output oriented models. The input CCR tries to decrease the maximum input level with a ratio of $\theta$ such that, at least, the same output is generated, i.e.:

$$
\begin{aligned}
& \min \quad \theta \\
& \text { subject to } \\
& \theta X_{p}-\sum_{j=1}^{n} \lambda_{j} X_{i j} \geq 0, \\
& \sum_{j=1}^{n} \lambda_{j} Y_{r j} \geq Y_{r p}, \\
& \lambda_{j} \geq 0, \quad j=1, \cdots, n .
\end{aligned}
$$

In the case of the output oriented DEA model, the objective is to maximize the output level, $\varphi$, by applying the same amount of input. The model can be formulated as follows,

$$
\begin{aligned}
& \min \varphi \\
& \text { subject to } \\
& \sum_{j=1}^{n} \lambda_{j} X_{i j} \leq X_{i p}, \\
& \sum_{j=1}^{n} \lambda_{j} Y_{j} \geq \varphi Y_{i p}, \\
& \lambda_{j} \geq 0, \quad j=1, \cdots, n .
\end{aligned}
$$

For the proposed study of this paper we used the following input and outputs for measuring the relative efficiencies of POSs and ATMs.

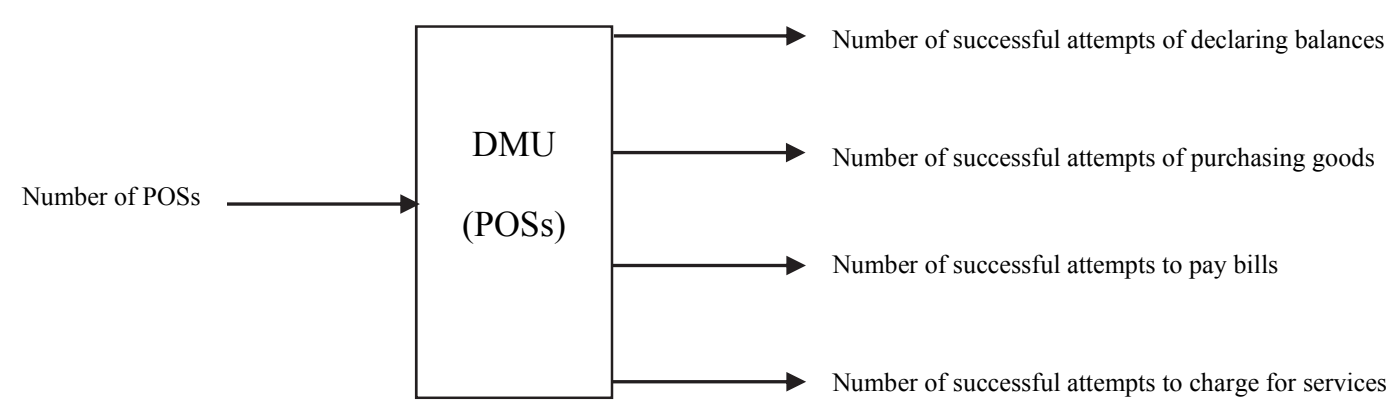

Fig. 1. The input and the output of DEA model for measuring the efficiency of POSs 


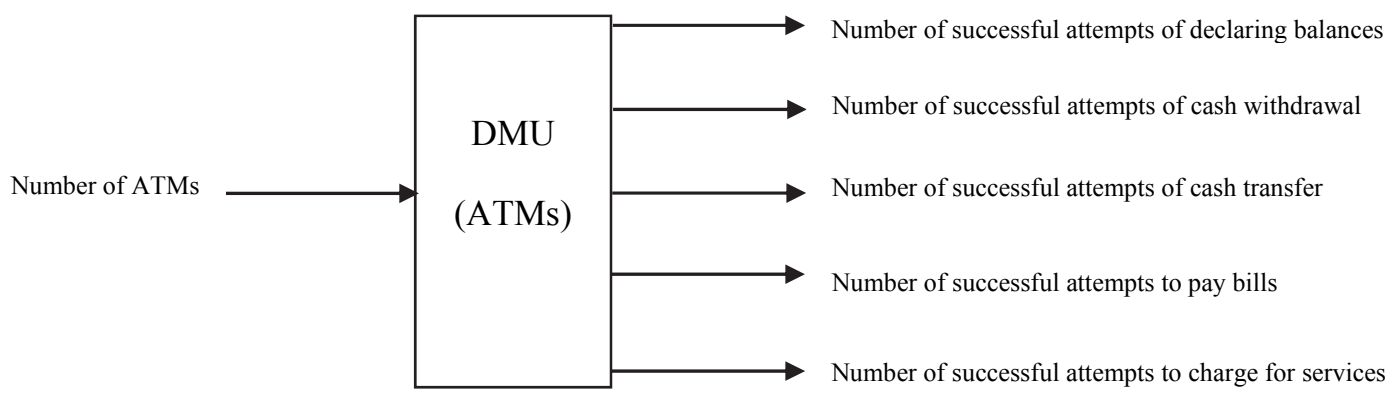

Fig. 2. The input and the output of DEA model for measuring the efficiency of ATMs

As we can observe from Fig. 1 and Fig. 2, for measuring the relative efficiencies of both ATM and POS, the proposed study uses the number of machines. There are also four inputs and five inputs considered for measuring the relative efficiencies of POS and ATM, respectively.

\section{Results}

The propsoed study of this paper has coded the DEA in Lingo software package and manged to solve both methods. In our survey, there were 602 ATMS and 599 POS. Fig. 3 shows the results of our survey for measuring the relative efficiencies of ATMs.

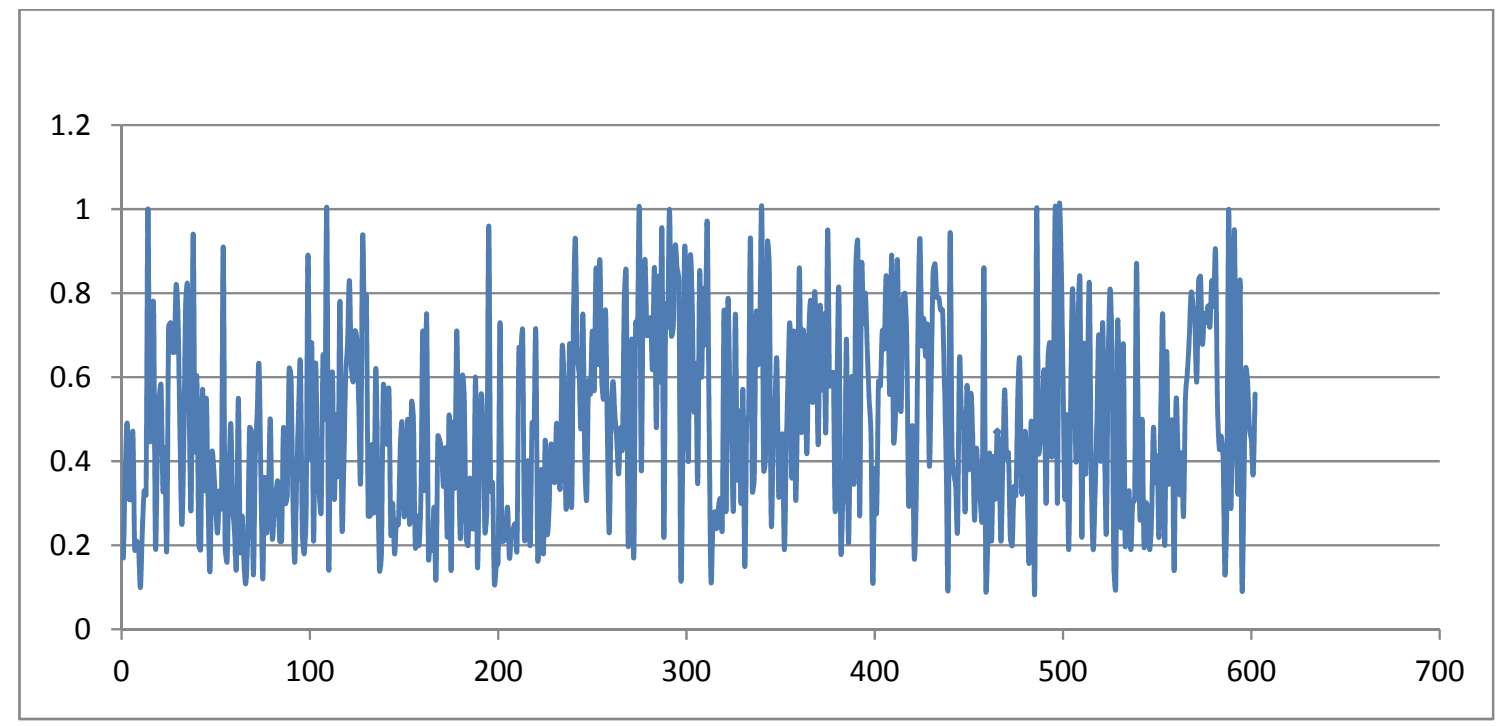

Fig. 3. The results of measuring the relative efficiency of different ATMs

As we can observe from the results of Fig. 3, there are significant varieties on efficiencies of various ATMs. In our survey, 65(11\%) of the ATMs have yielded efficiency score less than $0.2,181(30 \%)$ of them maintained efficiency score of less than $0.4,172(29 \%)$ worked at the efficiency of from 0.41 to $0.60,129(21 \%)$ had relatively high ratio of efficiency and only $55(9 \%)$ of them worked at efficiency between 0.80 and 1.0. In our survey, only a small portion of the ATMs was reported efficient. Finally, Fig. 4 demonstrates the relative efficiency of POSs. As we can see from the results of Fig. 4, there are significant varieties on efficiencies of various POSs. In our survey, 55(9\%) of the POSs have yielded efficiency score less than $0.2,240(40 \%)$ of them maintained efficiency score of less than $0.4,201(34 \%)$ worked at the efficiency of from 0.41 to $0.60,76(13 \%)$ had relatively high ratio of efficiency and only $24(4 \%)$ of them worked at efficiency between 0.80 and 1.0 . In our survey, only a small portion of the POSs was reported efficient. 


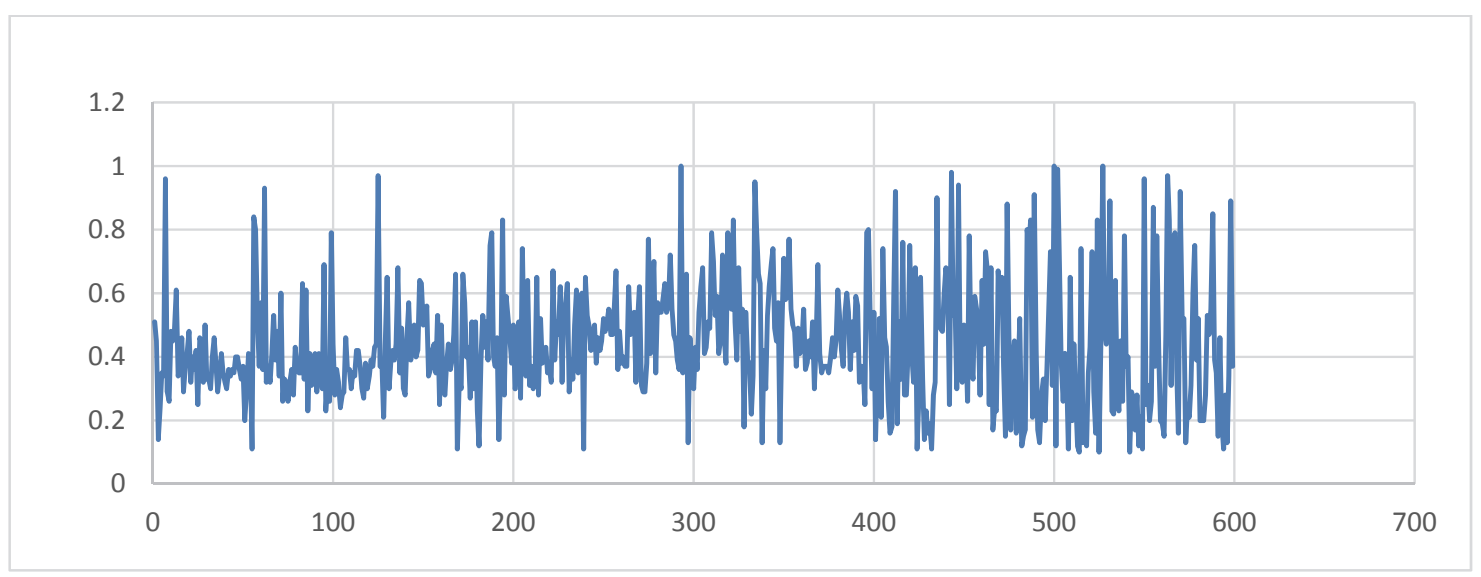

Fig. 4. The results of measuring the relative efficiency of different POSs

\section{Conclusion}

In this paper, we have presented an empirical investigation to measure the relative efficiencies of various ATM and POSs, which were used by one of the oldest Iranian banks in city of Tehran, Iran. The proposed study has applied traditional method of DEA technique to accomplish this task, where the number of facilities has been considered as input and various outputs have been considered as outputs. The results have indicated that most machines were perform poorly in terms of efficiency. There were different reasons for low performance of ATMs machines. One main reason is believed the existence of high competition among banks in city of Tehran, Iran. This problem also holds for POS machines since customers may have the opportunity to use several POS to make purchase and this reduces the relative efficiency of POSs. As a future study, one may look for appropriate facility location of ATMs in different parts of the city and we leave it as a future study.

\section{Acknowledgement}

The authors would like to thank the anonymous referees for constructive comments on earlier version of this paper.

\section{References}

Camanho, A. S., \& Dyson, R. G. (1999). Efficiency, size, benchmarks and targets for bank branches: an application of data envelopment analysis. Journal of the Operational Research Society, 50(9), 903-915.

Charnes A, Cooper, W. W., Rhodes, E. (1978). Measuring the efficiency of decision making units. European Journal of the Operational Research, 2, 429-44.

Charnes A, Cooper W. W., Lewin, A., Seiford, L. M. (1994). Data envelopment analysis: theory, methodology and applications. Massachusetts: Kluwer Academic Publishers.

Cook, W. D., Seiford, L. M., \& Zhu, J. (2004). Models for performance benchmarking: measuring the effect of e-business activities on banking performance. Omega, 32(4), 313-322.

Evans, K. R., Arnold, T. J., \& Grant, J. A. (1999). Combining Service and Sales at the Point of Customer Contact A Retail Banking Example. Journal of Service Research, 2(1), 34-49.

Pasiouras, F. (2008). International evidence on the impact of regulations and supervision on banks' technical efficiency: an application of two-stage data envelopment analysis. Review of Quantitative Finance and Accounting, 30(2), 187-223.

Yang, C., Tian, G., \& Ward, S. (2007). Security systems of point-of-sales devices. The International Journal of Advanced Manufacturing Technology,34(7), 799-815. 